\title{
Behavior and mechanism of enamine on quartz flotation
}

\author{
Shaohui Jing ${ }^{\mathrm{a}, \mathrm{c}}$, Dongsheng $\mathrm{He}^{\mathrm{a}, \mathrm{b}, *}$, Hong Wu${ }^{\mathrm{c}}$, Shuang Liu ${ }^{\mathrm{b}}$, Zhihao Xie \\ a Xingfa School of Mining Engineering, Wuhan Institute of Technology, Wuhan 430074 China \\ b Key Laboratory of Rare Mineral, Ministry of Land and Resources, Wuhan 430034 China \\ c State Key Laboratory of Powder Metallurgy, Central South University, Changsha 410083 China
}

*Corresponding author, e-mail: csuhy@126.com

Received 12 Dec 2019

Accepted 31 Jul 2020

\begin{abstract}
The mechanism of enamine on a quartz surface was investigated by pure mineral flotation tests combined with quartz surface wettability measurements, zeta potential tests and other analytical methods. The results show that the enamine flotation system had a quartz flotation $\mathrm{pH}$ range of 6.0-8.0 and a suitable collector concentration of $50 \mathrm{mg} / \mathrm{L}$. Under neutral conditions, when the collector concentration was low, the enamine was adsorbed on the quartz surface through a weak electrostatic force. Semi-micelle adsorption occurred when the collector concentration reached the critical micelle concentration value of $10 \mathrm{mg} / \mathrm{L}$. At enamine concentrations higher than $50 \mathrm{mg} / \mathrm{L}$, multilayer adsorption of enamine and quartz occurred. The infrared spectroscopy results showed that no new peaks were formed before and after the interaction between quartz and enamine and that the enamine was mainly physically adsorbed on the quartz surface.
\end{abstract}

KEYWORDS: enamine, quartz, flotation, adsorption mechanism

\section{INTRODUCTION}

Quartz is the main gangue of siliceous and silicatetype phosphate rock $[1,2]$. Removing silicon and aluminum impurities from phosphate rock is required to ensure the quality of the phosphate concentrate for further processing [3]. The positive flotation desiliconization process, which is based on fatty acid collectors [4], is a matured and industrialized technology $[5,6]$. This complicated process does, however, have a few problems which include high chemical consumption [7] and difficulty in handling the subsequent operations $[8,9]$. The reverse flotation desiliconization process, based on an amine cation collector [10], has advantages of low chemical dosage, good separation, excellent process index, easy dewatering of the concentrate, and the flotation principle of "floating less and suppressing more" [11], which allows broad application prospects $[12,13]$. He et al [14] studied the flotation of phosphate rock from a mine in the Hubei Province of China. They subjected the phosphate rock to a double reverse flotation process with DS- 1 as a demagnetization collector and mixed amine GDS-Y as an anti-flotation desiliconization collector. The final concentrate had a $\mathrm{P}_{2} \mathrm{O}_{5}$ grade of $31.23 \mathrm{wt} \%$, and a recovery of
$81.61 \%$ was achieved. Mohammadkhani et al [15] studied the beneficiation of a low-grade colloidal phosphate rock with a $5.01 \mathrm{wt} \% \mathrm{P}_{2} \mathrm{O}_{5}$ grade. Using the double reverse flotation process, desalination of sodium carbonate by sodium oleate removed carbonate while the cationic collector tallow fatty amine acetate (Armac-T), used for reverse flotation, removed siliceous gangue and obtained better flotation indicators. Even though literature on the antiflotation technology of amine cation collectors is available, the research on the mechanism between minerals and collector is insufficient. In this study, quartz flotation behavior with the enamine, cis-9octadecenylamine $\left(\mathrm{C}_{18} \mathrm{H}_{35} \mathrm{NH}_{2}\right)$, was investigated by flotation experiments, zeta potential analysis and infrared spectrometry. The results were used to propose and discuss the flotation mechanism in such a system.

\section{MATERIALS AND METHODS}

\section{Experiment materials}

High-purity quartz mineral was obtained from Zhengzhou Penny Chemical Reagent Factory. It was ground in a RK/XPM three-head grinder (Wuhan Rock Crush \& Grand Equipment Manufacture Co., Ltd, China), sieved to a particle size range of +38 to 


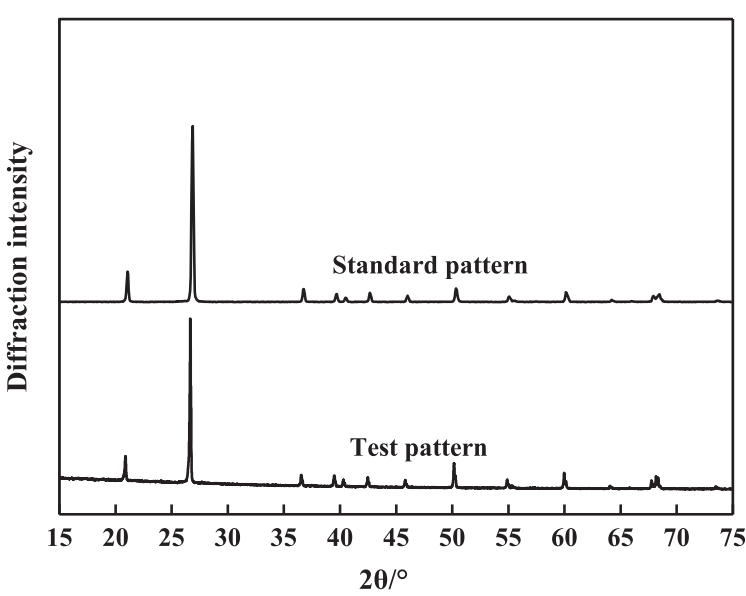

Fig. 1 XRD analysis of Quartz mineral sample.

$-75 \mu \mathrm{m}$, washed with hydrochloric acid solution, rinsed with deionized water and finally air-dried at room temperature. The XRD analysis of the quartz mineral sample and a $\mathrm{SiO}_{2}$ standard (Fig. 1) confirms that the material sample can be used as a single mineral with a $\mathrm{SiO}_{2}$ content greater than $95 \%$.

\section{Reagents}

Cis-9-octadecenylamine, glacial acetic acid, hydrochloric acid, sodium hydroxide and ethanol were of analytical grade and obtained from Shanghai Aladdin Biochemical Technology Co., Ltd, China. A 1:1 molar ratio mixture of enamine and glacial acetic acid was used to prepare an ammonium acetate solution of concentration of $4 \times 10^{-3} \mathrm{~mol} / \mathrm{L}$. $\mathrm{HCl}$ and $\mathrm{NaOH}$ solutions with concentrations of $0.1 \mathrm{~mol} / \mathrm{L}$ were used to adjust $\mathrm{pH}$.

\section{Flotation test}

Two grams of quartz was transferred to a XFG microflotation cell (Wuhan Prospecting Machinery Factory, China) containing $30 \mathrm{~mL}$ of deionized water. After stirring for $1 \mathrm{~min}$, the $\mathrm{pH}$ of the subsequent pulp was adjusted by adding $\mathrm{HCl}$ or $\mathrm{NaOH}$, followed by stirring for $2 \mathrm{~min}$. Thereafter a known amount of enamine collector (concentration $4 \times 10^{-3} \mathrm{~mol} / \mathrm{L}$ in aqueous solution) was added to the pulp and conditioned for $2 \mathrm{~min}$. After $3 \mathrm{~min}$ of flotation, the collected foam product was filtered, dried and weighed. The recovery is defined as the dry mass of quartz collected expressed as a percentage of the dry mass of sample initially present in the flotation cell. The effect of $\mathrm{pH}$ (range: 2-12) and enamine concentration (range: $10-110 \mathrm{mg} / \mathrm{L}$ ) on the recov-

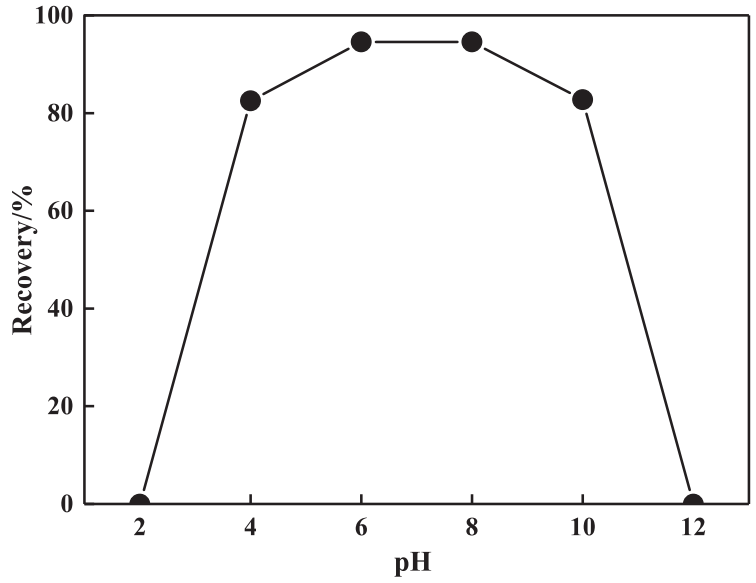

Fig. 2 Effect of $\mathrm{pH}$ on quartz recovery at $50 \mathrm{mg} / \mathrm{L}$ enamine.

ery of quartz was studied.

\section{Analysis methods}

The contact angle measurements were carried out by the seat drop method using a JC2000DM contact angle measuring instrument on quartz powder samples at different enamine dosages. The average value of multiple measurements was taken as the result. Infrared spectroscopy was performed on a Nicolet-6700 Fourier transform infrared spectrometer in the range of $400-4000 \mathrm{~cm}^{-1}$ using $\mathrm{KBr}$ pellets. The zeta potential of samples was measured at $25^{\circ} \mathrm{C}$ with a Nano-ZS90 Zeta Meter at different $\mathrm{pH}$ values. A JK99CM automatic surface tension meter was used to measure the surface tension of the solution at different enamine dosages.

\section{RESULTS AND DISCUSSION}

The floating behavior of quartz was studied in a micro-flotation cell with an enamine collector at different $\mathrm{pH}$ values and enamine dosages.

\section{Effect of pH on quartz recovery}

Fig. 2 illustrates the recovery of quartz at different $\mathrm{pH}$ values when the enamine collector concentration is $50 \mathrm{mg} / \mathrm{L}$. We found the recovery rate of quartz first increased with the increase of $\mathrm{pH}$, then stabilized and finally decreased. When the $\mathrm{pH}$ ranged from 2.0 to 6.0, the enamine had good recovery ability for quartz and reached a maximum value of about $94 \%$. In the $\mathrm{pH}$ range of $6.0-8.0$, the recovery of quartz changed very little. At $\mathrm{pH}$ values above 8.0, quartz recovery gradually decreased with a further increase in $\mathrm{pH}$, and the downward trend 


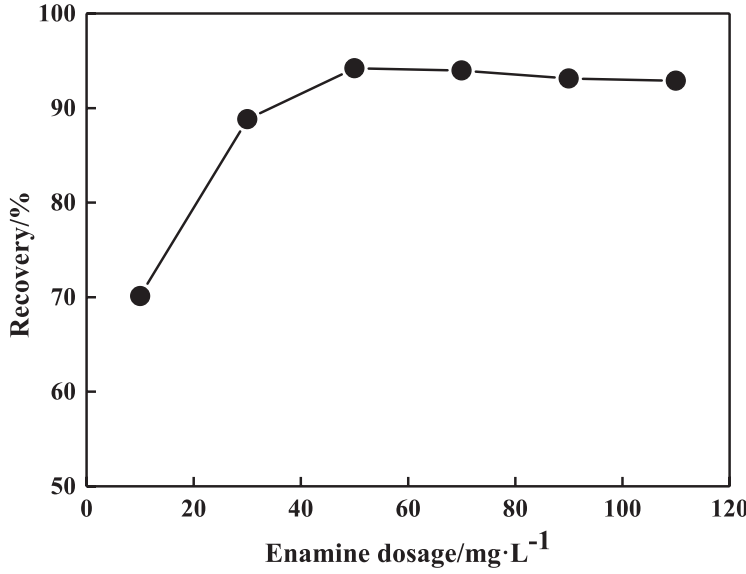

Fig. 3 Effect of the amount of enamine on the recovery of quartz at $\mathrm{pH} 6.5$.

was most significant after $\mathrm{pH}$ 10.0. Therefore, under conditions of weak acidity and weak alkalinity, the enamine has a strong effect on quartz recovery with the highest recoveries of approximately $94 \%$ being achieved at $\mathrm{pH} 6$ to 8 . It is therefore suitable to float quartz in this $\mathrm{pH}$ range.

\section{Effect of collector dosage on quartz recovery}

The relationship between the recovery of quartz and the amount of enamine at $\mathrm{pH} 6.5$ is shown in Fig. 3. At pH 6.5, the recovery of quartz first increased and then stabilized with increasing of enamine. At enamine dosages of 10,30 and $50 \mathrm{mg} / \mathrm{L}$, the recoveries were $70.14 \%, 88.82 \%$ and $94.21 \%$, respectively. Increasing the dosage of amine beyond $50 \mathrm{mg} / \mathrm{L}$ had little effect on the recovery of quartz and therefore presented the optimum enamine dosage at this $\mathrm{pH}$. Increasing dosage to above $50 \mathrm{mg} / \mathrm{L}$ will lead to an increase in operating cost with no real advantage to remove the quartz.

To explain the flotation behavior of quartz in enamine system, cis-9-octadecenylamine $\left(\mathrm{C}_{18} \mathrm{H}_{35} \mathrm{NH}_{2}\right)$, the wettability, infrared spectrograms and zeta-potential of the colloidal system were studied.

\section{The wettability of quartz surface}

Fig. 4 presents the relationship between the amount of enamine and the contact angle of quartz at $\mathrm{pH}$ 6.5. The contact angle is a measure of the wettability of a mineral, and the lower the contact angle the easier it is to wet the mineral surface. In the absence of enamine, the contact angle of the quartz surface was approximately $20^{\circ}$. The contact angle of the solution on the surface of the quartz increases

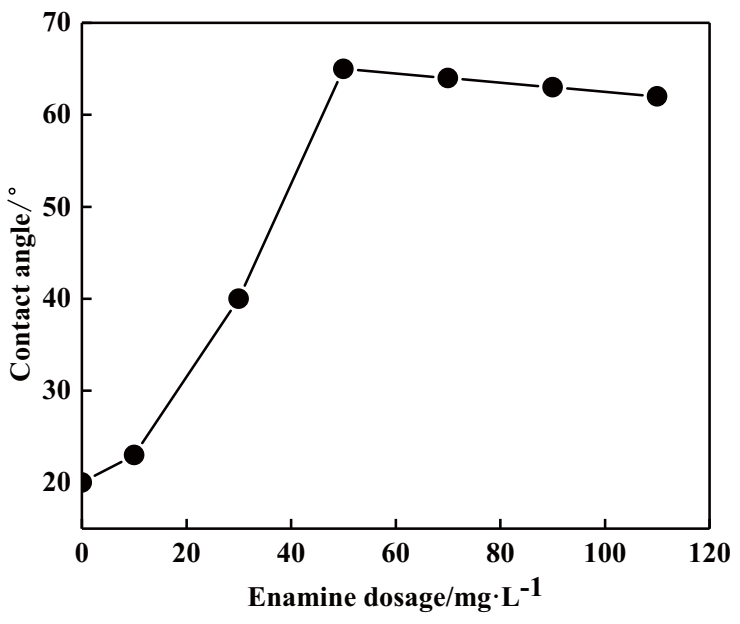

Fig. 4 The relationship between the concentration of enamine and the contact angle of quartz at $\mathrm{pH} 6.5$.

with the amount of enamine present in solution, indicating an increase in the hydrophobicity of the quartz. The contact angle reaches a maximum of $65^{\circ}$ when the concentration of enamine is $50 \mathrm{mg} / \mathrm{L}$. The influence of the enamine concentration on the contact angle was expected as at higher concentrations a larger amount of enamine adsorbs onto the surface of quartz leading to an increase in contact angle. After the contact angle reached $65^{\circ}$, an additional increase in the enamine dosage had no further effect on it. This is probably because the quartz surface was saturated with enamine and could not adsorb any additional chemicals. These results explain why the recovery of quartz in the flotation experiments increased up to a dosage of $50 \mathrm{mg} / \mathrm{L}$ and then stayed constant beyond this dosage at about $93 \%$.

\section{Infrared analysis of the influence of enamine collectors on quartz}

Fig. 5 shows a comparison of the infrared spectra of enamine $\left(\mathrm{C}_{18} \mathrm{H}_{35} \mathrm{NH}_{2}\right)$, quartz and quartz with enamine. It is known from the molecular formula $\mathrm{C}_{18} \mathrm{H}_{35} \mathrm{NH}_{2}$ (9-octadecene amine) (curve (a)) that $3344.55 \mathrm{~cm}^{-1}$ is the $\mathrm{N}-\mathrm{H}$ stretching vibration peak of $-\mathrm{NH}_{2}$ and that $2924.28 \mathrm{~cm}^{-1}$ and $2854.17 \mathrm{~cm}^{-1}$ are the asymmetric stretching absorption peak and symmetric stretching vibration absorption peak of $-\mathrm{CH}_{2}-$, respectively. $1644.28 \mathrm{~cm}^{-1}$ is the $\mathrm{C}=\mathrm{C}$ stretching vibration peak, $1398.59 \mathrm{~cm}^{-1}$ is the bending vibration absorption peak of $-\mathrm{CH}_{3}$, and $1072.92 \mathrm{~cm}^{-1}$ is the stretching vibration peak of $\mathrm{C}-\mathrm{N}$ [16]. On curve (b), $3434.10 \mathrm{~cm}^{-1}$ is the asymmetric stretching vibration peak of the hy- 


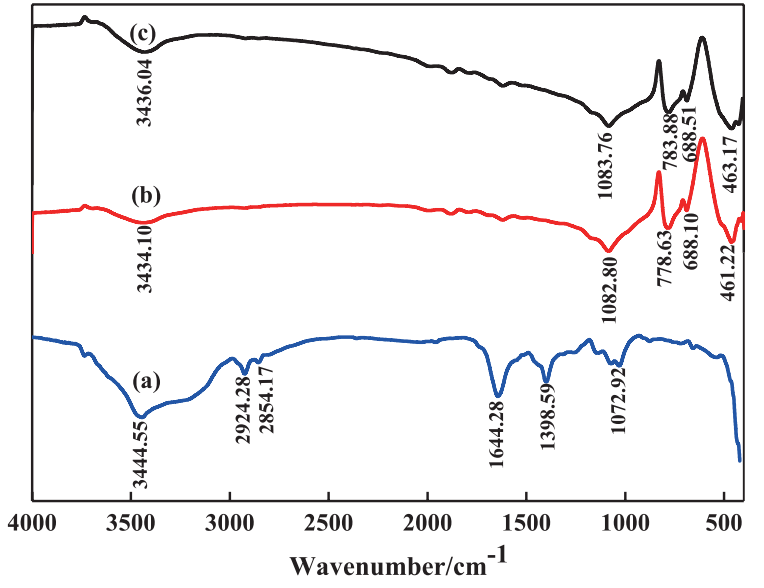

Fig. 5 Infrared spectra of (a) enamine, (b) quartz and (c) quartz+enamine.

droxyl group adsorbed on the quartz surface and the asymmetric stretching vibration peak of $\mathrm{Si}-\mathrm{O}$ at $1082.80 \mathrm{~cm}^{-1}, 778.63 \mathrm{~cm}^{-1}$ and $688.10 \mathrm{~cm}^{-1}$ is the symmetric stretching vibration peak of $\mathrm{Si}-\mathrm{O}-\mathrm{Si}$, and $461.22 \mathrm{~cm}^{-1}$ is the bending vibration absorption peak of $\mathrm{Si}-\mathrm{O}$ [17].

After the interaction between quartz and the collector enamine (curve $\mathrm{c}$ ), the $\mathrm{N}-\mathrm{H}$ group of the enamine molecule at $3444.55 \mathrm{~cm}^{-1}$ was affected by hydrogen bonding, leading to the appearance of the hydroxyl vibration peak at $3436.04 \mathrm{~cm}^{-1}$. The asymmetric stretching vibration peak of $\mathrm{Si}-\mathrm{O}$ was shifted from $1082.80 \mathrm{~cm}^{-1}$ to $1083.76 \mathrm{~cm}^{-1}$; the $\mathrm{Si}-\mathrm{O}-\mathrm{Si}$ symmetric stretching vibration peak at $778.63 \mathrm{~cm}^{-1}$ and the bending vibration absorption peak of $\mathrm{Si}-\mathrm{O}$ at $461.22 \mathrm{~cm}^{-1}$ were shifted to $783.88 \mathrm{~cm}^{-1}$ and $463.17 \mathrm{~cm}^{-1}$, respectively. Therefore, no new peaks were generated after the action of quartz and enamine, and the peaks before interaction were only slightly shifted, indicating that the enamine did not produce chemisorption on the quartz surface.

\section{Zeta potential analysis}

Fig. 6 illustrates changes in zeta potential before and after the interaction of enamine and quartz at a standard temperature $\left(25^{\circ} \mathrm{C}\right)$ and an enamine concentration of $50 \mathrm{mg} / \mathrm{L}$. Curve (a) shows that the isoelectric point of quartz is $\mathrm{pH} 2.3$ and is consistent with literature $[18,19]$. When the $\mathrm{pH}$ is larger than 2.3 , the surface of the quartz becomes negatively charged, and as the $\mathrm{pH}$ value increases, the surface electronegativity of quartz gradually increases. At $\mathrm{pH} 12.0$, the zeta potential of quartz is $-61.8 \mathrm{mV}$.

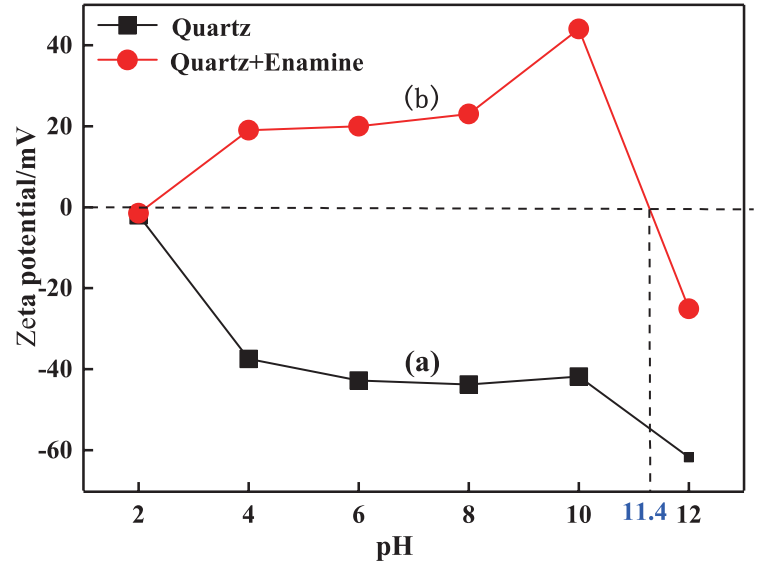

Fig. 6 Effect of enamine on Zeta potential of quartz surface.

After addition of the enamine (curve (b)), the zeta potential of the quartz colloid changed from negative to positive, indicating that the enamine was adsorbed on the surface of the quartz and changed the electrical properties of the quartz surface. When the $\mathrm{pH}$ was 10.0, the zeta potential of the quartz changed from $-41.8 \mathrm{mV}$ to $44 \mathrm{mV}$, a variation of $85.8 \mathrm{mV}$. As an amine cation collector, the enamine can exchange and adsorb the hydrolysate $\mathrm{RNH}_{3}^{+}$or $\mathrm{RNH}_{2} \cdot \mathrm{RNH}_{3}^{+}$with the surface of the quartz under acidic and neutral conditions [20,21], causing the zeta potential of the quartz surface to shift positively. Under alkaline conditions, the enamine is mainly in the form of amine molecules, $\mathrm{RNH}_{3}^{+}$concentration decreases, and $\mathrm{OH}^{-}$concentration increases in solution. Thus, the positive electroconductivity of quartz is weakened, and the amount of negative charge is increased, resulting in a lower potential on the quartz surface. When the $\mathrm{pH}$ equals to 11.4 , the zeta potential changes from positive to negative, which may be due to the large amount of $\mathrm{OH}^{-}$in the solution being adsorbed on the outer layer, causing the surface of the quartz to change electrically.

\section{Surface tension analysis}

The surface tension measurements at different amounts of enamine in aqueous solution at standard temperature $\left(25^{\circ} \mathrm{C}\right)$ are shown in Fig. 7a. Fig. $7 \mathrm{~b}$ shows the plot of the logarithm of enamine concentration versus surface tension for determining the critical micelle concentration (CMC) in the solution. Surface tension is a measure of the surface activity of different substances, and the magnitude of surface activity directly reflects the strength of the collector's flotation ability $[22,23]$. Using the loga- 


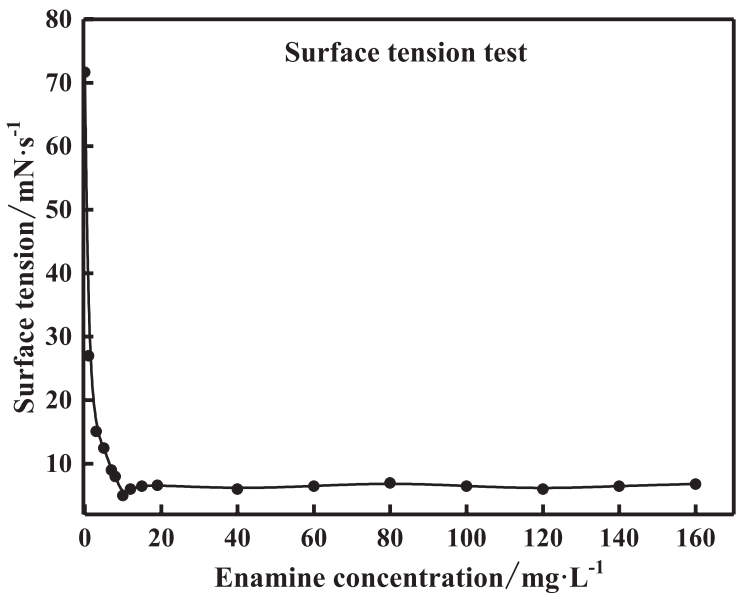

(a)

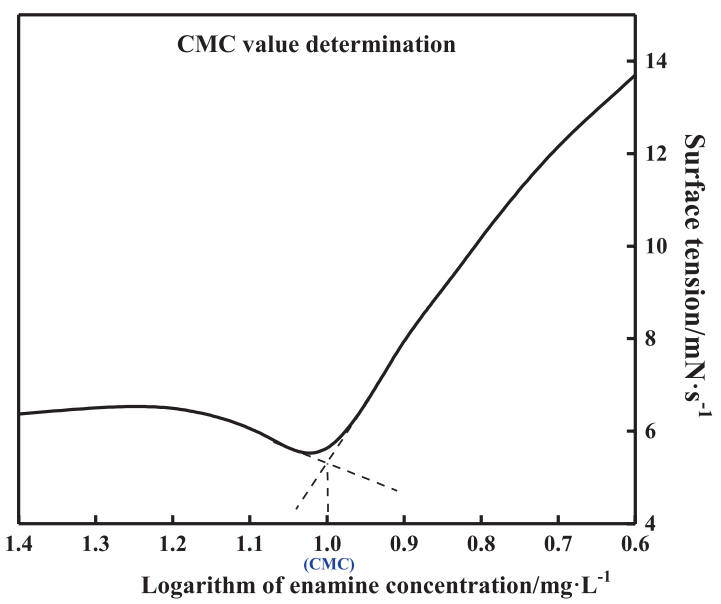

(b)

Fig. 7 Surface tension test diagram. (a) Surface tension test. (b) CMC value determination.

rithm of surface tension and sample concentration as a graph, when the surface adsorption reaches saturation, the curve shows a turning point. At this time, the concentration is CMC. Therefore, the size of the surface tension and the formation state can be judged by comparing the CMC before and after formation. Fig. 7a shows the surface tension of pure water to be $71.63 \mathrm{mN} / \mathrm{s}(0 \mathrm{mg} / \mathrm{L}$ enamine concentration). With the addition of enamine, the surface tension of the aqueous solution drops rapidly as the amount of enamine in solution increases and reaches a minimum value of $5.43 \mathrm{mN} / \mathrm{s}$. Increasing the dosage beyond this point leads to a slight increase in surface tension, and thereafter it remains unchanged irrespective of the amount of enamine added. From Fig. 7b, the critical micelle concentration was at $10 \mathrm{mg} / \mathrm{L}$.

\section{Enamine and quartz interaction model}

The results of the enamine dosage test and related mechanism analysis was used to propose an adsorption model for the action between enamine and quartz (Fig. 8).

Under hydrophobic action, the surfactant can spontaneously aggregate in water with an increase of its own concentration and pass through the polymerization process from monomer to micelle $[24,25]$. Using results from this study combined with the relevant literature [26,27], the adsorption model of enamine and quartz interaction is described as follows:

When the concentration of enamine was very low, it existed in the form of a monomer, and a few enamine molecules were scattered on the surface of the quartz due to electrostatic force (Fig. 8a). As the concentration of enamine increased, the enamine molecules adhered to quartz surface in a monolayer adsorptive state (Fig. 8b) which made the surface tension of the solution drop sharply (Fig. 7a). When the amount of enamine reached the critical micelle concentration of $10 \mathrm{mg} / \mathrm{L}$, some enamine molecules formed micelle-like aggregates with the association center of polymer carbon chains, which increased the surface coverage of quartz (Fig. 8c). When the concentration of enamine continuously increased, some of the adsorption forms of enamine reversed and formed opposite orientation adsorption by hydrophobic interaction combined with monolayer adsorption on quartz surface while micelle-like aggregates grew together and formed semi-micelle adsorption by association (Fig. 8d). When the concentration of enamine was higher, a complete and stable micelle structure was formed in the solution, and the adsorption of enamine on the solid-liquid interface reached saturation. Finally, the contact angle of enamine on the quartz surface decreased, the hydrophobicity of quartz reduced, and the recovery decreased slightly (Fig. 8e). Therefore, the model visualizes the flotation behavior of quartz in the enamine flotation system and agrees with the test results of the effect of amount of enamine on quartz recovery and contact angle (Figs. 3 and 4).

\section{CONCLUSION}

In the enamine flotation system, the $\mathrm{pH}$ of the enamine is in the range of 6.0 to 8.0, and the enamine has a strong effect on the collection of quartz. When the amount of enamine is $50 \mathrm{mg} / \mathrm{L}$, the recovery rate of quartz flotation can reach $94 \%$. When the $\mathrm{pH}$ is 6.5 and the enamine concentration 


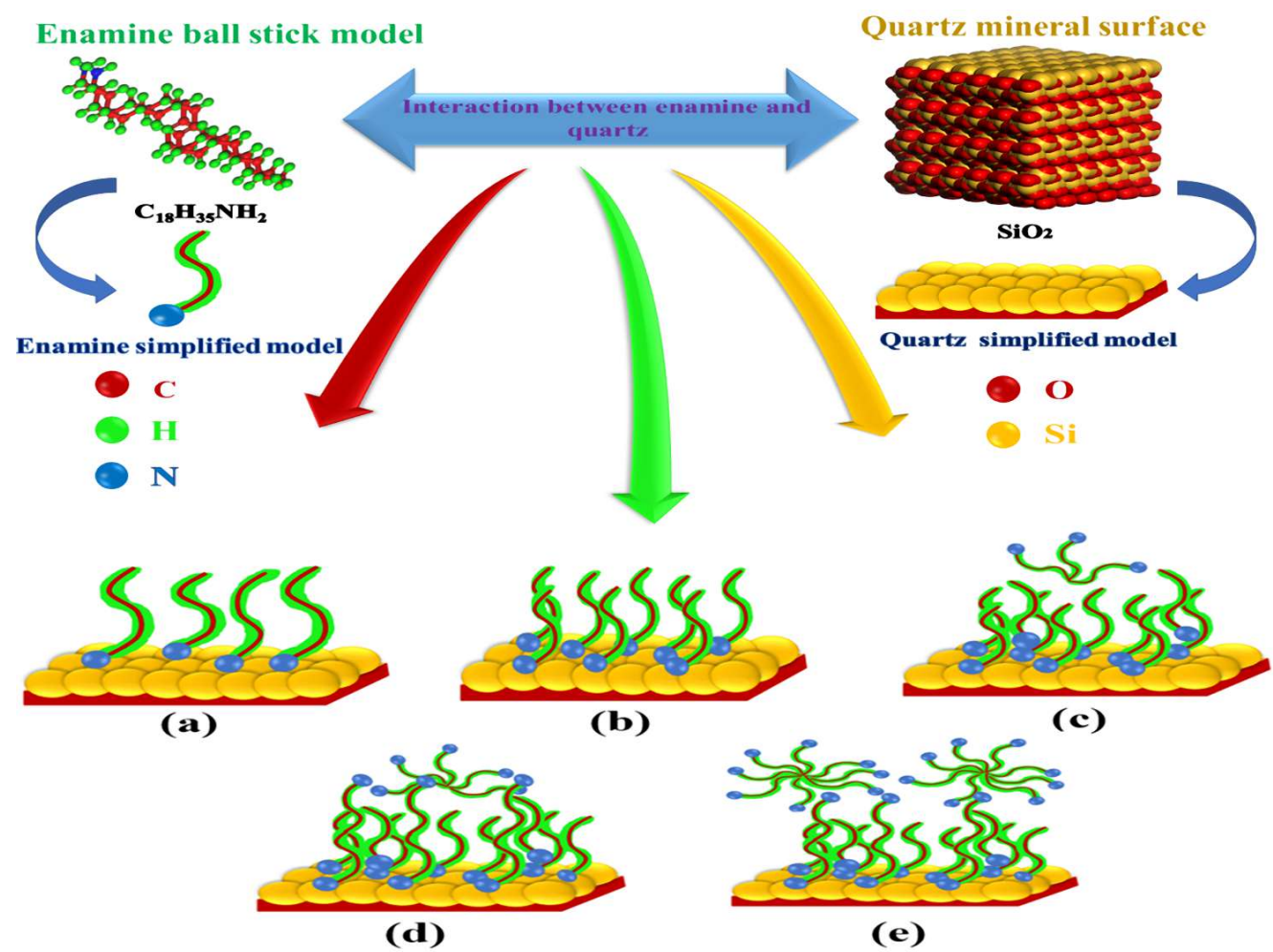

Fig. 8 Adsorption configuration of enamine on quartz surface.

is above $50 \mathrm{mg} / \mathrm{L}$, the enamine is saturated on the surface of the quartz. Above $\mathrm{pH}$ 10.0, the enamine is physically adsorbed on the surface of the quartz by hydrogen bonding. The results of infrared spectroscopy showed that no new peak was produced after the interaction between quartz and enamine, and enamine was not chemisorbed on the quartz surface. The surface tension test shows that the critical micelle concentration of the enamine is $10 \mathrm{mg} / \mathrm{L}$. After the enamine concentration reaches $\mathrm{CMC}$, the enamine forms a monolayer adsorption micelle or a hemi-gel association structure. The adsorption model diagram further illustrates the adaptation to the adsorption state on the enamine surface; as the enamine concentration increases, the solution eventually forms a complete doublelayer micelle or micelle structure. The adsorption of enamine at the solid-liquid interface tends to be stable.

Acknowledgements: The authors would like to acknowledge Key Laboratory of Rare Mineral, Ministry of Land and Resources for financial support through an open fund (KRLM-KF202002) and thank Hubei Technology Innovation Project (Foreign Science and Technology Cooperation; No. X19S012); Hubei Tailings (Slag)
Resource Utilization Engineering Technology Research Center Project (No. 2019ZYYD070), the 10th Graduate Education Innovation of Wuhan Institute of Technology (CX2018087), Wuhan Institute of Technology Innovation Training Program (201810490022) for important support.

\section{REFERENCES}

1. Jing SH, He DS, Xie ZH (2018) Investigation of the depressing effect of $\mathrm{PO}_{4}^{3-}$ on quartz in oleyl amine flotation system. Conser Util Miner Resour 3, 135-139.

2. Huang ZQ, Cheng C, Liu ZW, Zeng HQ, Feng B, Zhong H, Luo WH, Hu, YJ, et al (2019) Utilization of a new Gemini surfactant as the collector for the reverse froth flotation of phosphate ore in sustainable production of phosphate fertilizer. J Clean Prod 221, 108-112.

3. Zhu HL, Qin WQ, Chen C, Chai LY, Li LS, Liu SJ, Zhang T (2018) Selective flotation of smithsonite, quartz and calcite using alkyl diamine ether as collector. T Nonferr Metal Soc 28, 163-168.

4. Chang QW (2016) Application of a new highefficiency and low-temperature-resistant collectors in reverse flotation desilication of iron ore. Metal Mine 12, 109-112. 
5. Huang ZQ, Cheng C, Li K, Zhang SY, Zhou JR, Luo WH, Liu ZW, Qin WW, et al (2020) Reverse flotation separation of quartz from phosphorite ore at low temperatures by using an emerging Gemini surfactant as the collector. Sep Purif Technol 246, ID 116923.

6. Qin WQ, Wu JJ, Jiao F (2017) Mechanism of different particle sizes of quartz activated by metallic ion in butyl xanthate solution. Cent South Univ 24, 56-61.

7. Shi TY, Zhang Q (2017) Effects of crystal structure and surface properties on quartz floatability. Acta Miner Sin 37, 333-341.

8. Liu WB, Liu WG, Zhao Q, Shen YB, Peng, X (2020) Design and flotation performance of a novel hydroxy polyamine surfactant based on hematite reverse flotation desilication system. $J$ Mol Liq 301, ID 112428.

9. Zhu HL, Deng HB Chen C (2015) Flotation separation of andalusite from quartz using sodium petroleum sulfonate as collector. Trans Nonferrous Met Soc China 25, 1279-1285.

10. Li XB, Zhang Q, Hou B, Ye JJ, Mao S, Li XH (2017) Flotation separation of quartz from collophane using an amine collector and its adsorption mechanisms. Powder Technol 318, 224-229.

11. Wang L, Sun W, Liu RQ (2014) Mechanism of separating muscovite and quartz by flotation. Cent South Univ 21, 3596-3602.

12. Zhang XR, Zhu YG, Xie Y, Shang YB, Zheng GB (2017). A novel macromolecular depressant for reverse flotation: synthesis and depressing mechanism in the separation of hematite and quartz. Sep Purif Technol 186, 175-181.

13. Sahoo H, Rath SS, Das B, Mishra BK (2016) Flotation of quartz using ionic liquid collectors with different functional groups and varying chain lengths. Miner Eng 95, 107-112.

14. He DS, Liu X, Dai J, Zou Z, Qin F, Yu H (2017) Floatation Behavior and Mechanism of Quartz Using Amphoteric Collector LDS. Conser Utiliz Miner Res 2, 47-50.

15. Mohammadkhani M, Noaparast M, Shafaei SZ, Amini A, Amini E, Abdollahi H (2011) Double reverse flotation of a very low grade sedimentary phosphate rock, rich in carbonate and silicate. Int J Miner Process 100, 157-165.

16. Liu Z, Sun Z, Yu JG (2015) Investigation of dodecylammonium adsorption on mica, albite and quartz surfaces by QM/MM simulation. Mol Phy 113, 3423-3430.

17. Jin JX, Long YY, Gao HM, Ren ZJ (2019) Flotation behavior and mechanism of andalusite and kyanite in the presence of sodium oleate. Sep Sci Technol 54, 1803-1814.

18. Feng B, Wang P, Lu Y, Feng Q (2016) Role of sodium hexametaphosphate in flotation of a nickel ore. Physicochem Probl Mi 52, 170-181.

19. Kowalczuk, $P B$ (2015) Flotation and hydrophobicity of quartz in the presence of hexylamine. Int $J$ Miner Process 140, 66-71.

20. Garvey SL, Dietz ML (2014) Ionic liquid anion effects in the extraction of metal ions by macrocyclic polyethers. Sep Purif Technol 123, 145-152.

21. Cheng C, Huang ZQ, Zhang RR, Zhou JR, Liu ZW, Zhong H, Wang HL, Kang ZM, et al (2020) Synthesis of an emerging morpholine-typed Gemini surfactant and its application in reverse flotation carnallite ore for production of potash fertilizer at low temperature. J Clean Prod 261, ID 121121.

22. Jin JX, Gao HM, Chen XM, Peng YJ, Min FF (2016) The flotation of aluminosilicate polymorphic minerals with anionic and cationic collectors. Miner Eng 99, 123-132.

23. Zhao Z, Wang QF (2010) Progress on methods of measuring surface active agent's critical micelle concentration. Pract Pharm Clin Remed 13, 140-144.

24. Vidyadhar A, Rao KH (2007) Adsorption mechanism of mixed cationic/anionic collectors in feldsparquartz flotation system. J Colloid Interface Sci 306, 195-204.

25. Mohr A, Nylander T, Piculell L, Lindman B, Boyko V, Bartels FW, Kurkasiebert V (2012) Mixtures of cationic copolymers and oppositely charged surfactants: effect of polymer charge density and ionic strength on the adsorption behavior at the silica-aqueous interface. ACS Appl Mater Inter 4, 1500-1511.

26. Huang ZQ, Cheng C, Liu ZW, Feng B, Hu YJ, Luo WH, He GH, Yu XY, et al (2019) Highly efficient potassium fertilizer production by using a gemini surfactant. Green Chem 21, 1406-1411.

27. Karimi M, Almaamari RS, Ayatollahi S, Mehranbod N (2016) Impact of sulfate ions on wettability alteration of oil-wet calcite in the absence and presence of cationic surfactant. Energ Fuel 30, 819-829. 